\title{
Mechanical and Structural Stability of an Extruded Starch-protein-polyol Food System
}

\author{
Javier I. Enrione (Corresponding author) \\ Departamento de Ciencia y Tecnología de Alimentos, Facultad Tecnológica \\ Universidad de Santiago de Chile, Av. Ecuador 3769, Santiago, Chile \\ Tel: 56-2718-4518Ｅ-mail: javier.enrione@usach.cl \\ Paulo C. Díaz \\ Departamento de Ciencia y Tecnología de Alimentos, Facultad Tecnológica \\ Universidad de Santiago de Chile, Av. Ecuador 3769, Santiago, Chile \\ Tel: 56-2718-4524Ｅ-mail: paulo.diazca@usach.cl \\ Silvia B. Matiacevich \\ Departamento de Ciencia y Tecnología de Alimentos, Facultad Tecnológica \\ Universidad de Santiago de Chile, Av. Ecuador 3769, Santiago, Chile \\ Tel: 56-2718-4517 E-mail: silvia.matiacevich@usach.cl
}

Sandra E. Hill

Division of Food Sciences, The University of Nottingham

Sutton Bonington Campus, Loughborough LE12 5RD, United Kingdom

Tel: 44-115-951-6145 E-mail: sandra.hill@nottingham.ac.uk

Received: January 5, 2012

Accepted: January 19, 2012 Published: May 1, 2012

doi:10.5539/jfr.v1n2p224

URL: http://dx.doi.org/10.5539/jfr.v1n2p224

The research was supported by Conicyt Fondecyt Grant $N^{\circ} 1110607$. The authors would gratefully acknowledge the scientific support of the Division of Food Sciences from the University of Nottingham

\begin{abstract}
The objective of this work was to assess the structure stability of a starch-protein-polyol based food product manufactured by extrusion using texture analysis (TA), mechanical spectroscopy (DMTA), differential calorimetry (DSC) and X-ray diffraction. An accelerated storage trial showed an increase in the compression force from $\sim 25 \mathrm{~N}$ to $\sim 82 \mathrm{~N}$ after 120 days at $37{ }^{\circ} \mathrm{C}$. The decrease in tan $\delta$ values from $\sim 0.65$ to $\sim 0.40$, from DMTA, suggested a reduction in the amorphous fraction of the starch present in the formulation. This data was supported by DSC, which showed an irreversible endothermic peak at $\sim 58{ }^{\circ} \mathrm{C}$ with an associated melting enthalpy $(\Delta \mathrm{H}) \sim 2.1 \mathrm{~J} / \mathrm{g}$. The kinetic was modeled by the Avrami equation as an empirical approximation giving the parameter $G\left(\mathrm{~h}^{-1}\right) \sim 1.62 \mathrm{E}-02$. This data indicated that the retrogradation of the starchy component is the main mechanism driving the changes in texture of the whole product, confirming the importance of its structuring functionality in this type of formulations.
\end{abstract}

Keywords: Starch, Polyol, Extrudate, Retrogradation

\section{Introduction}

Intermediate moisture food products provide important advantages over wet products in terms of palatability and shelf life. They show attractive textural attributes at water activities (Aw) lower than 0.7 , minimizing spoilage 
due to microorganisms (Fennema, 1996). This characteristic, commonly found in foods such as confectioneries, is also being applied to pet-care formulations such as flavored tooth-cleaner chews and meat-like treats, where mechanical properties are important quality attributes together with nutritional value. The composition of these formulations is commonly based on cereals as structure forming components. Other ingredients include proteins, lipids and low molecular weight components as plasticizers, which contribute to the rubber-like behavior at ambient temperature. Although these products are microbiologically stable during storage, an increase in the hardness has been reported (McMahon, Adams \& McManus, 2009). This behavior would have an effect on the product's digestibility, increasing the risk of dental and digestive tract injuries (Torney, Unlu, Willcocks, Zubair $\&$ Bierer, 2009). Therefore, understanding the mechanisms driving these changes seems important in order to improve product formulation and shelf life. Due to their complexity, very little information is found in the literature on the fundamentals of the structural stability of real food products, limiting their study to empirical methods, which makes the understanding of ageing phenomena difficult and incomplete. Li, Szlachetka, Chen, Lin and Ruan (2008) studied the hardening of a high content protein bar by textural analysis and nuclear magnetic resonance (NMR), showing changes in molecular mobility during storage but with no clear explanation of its occurrence. More fundamental studies looking at mechanisms driving the structural stability and its kinetics are applied to simpler models systems.

Van Soest and Knooren (1997) studied the changes in mechanical properties of potato starch-gycerol based extruded sheet during storage, showing a correlation between an increase in elastic modulus and crystallinity dependent on water content, plasticizer concentration, and glass transition temperature (Tg). Farhat, Blanshard and Mitchell (2000) analyzed the retrogradation kinetics of waxy maize starch extrudates, observing an increase in crystallinity and a decrease in molecular mobility after 40 hours. They determined a strong dependence of retrogradation on water content and storage temperature. Kingcam, Devahastin and Chiewchan (2008) studied the effect of pre-treatments (blanching, freezing and thawing) on the degree of starch retrogradation of dried potato chips, showing that an increase in degree of crystallinity led to an increase in hardness and toughness produced by the formation of crystalline regions during the starch retrogradation.

In the case of the stability of intermediate and high moisture foods $(>\sim 10 \%)$, they can undergo changes in their structure which can be related to the reordering of the amorphous polymer chains towards a crystalline structure if stored at temperatures above their Tg (Farhat, Blanshard, Decamps, \& Mitchell, 2000; Jouppila, Kansikas, \& Roos, 1998; Mizuno, Mitzuiki, \& Motoki, 1998). For example, it is generally accepted that starch retrogradation significantly contributes to bread staling, demonstrated by the formation of crystal-like structures using differential scanning calorimetry and X-ray diffraction (Gray \& Bemiller, 2003; Jagannath, Jayaraman, Arya, \& Somashekar, 1998; Karim, Norziah \& Seow, 2000).

In terms of the prediction of the ageing phenomenon, several theories have been developed to describe the kinetics of crystallization of starch-based products, where the Avrami equation (Avrami, 1940) has been the one most widely used. Jouppila et al. (1998) studied the crystallization kinetics of amorphous corn starch at various temperatures and water content, and from an analysis of the parameters of the Avrami equation concluded that crystallization is faster at higher temperatures and $\mathrm{T}-\mathrm{Tg}>0$ conditions. Takaya, Sano and Nishinari (2000) analyzed the retrogradation of the gelatinized corn starch system and from the slope analysis of the Avrami equation showed that starch gels, especially the amylose fraction, retrograde immediately on cooling, followed by rod-like growth of crystals. Kun, Ping, Li-Jun, Zhan-Hui and Li-Te (2007) studied the kinetics of staling of Man-tou (special kind of Chinese bread) using the Avrami equation and found that the hardening rate was higher than the crystallization rate, suggesting that starch crystallization is not the only factor that increases the hardness of this product.

The aim of this work was to identify and study the mechanism driving the changes in mechanical properties of an intermediate moisture starch-protein-poyol based product during storage using fundamental techniques including dynamic mechanical thermal analysis (DMTA), differential scanning calorimetry (DSC) and wide angle X-ray diffraction (WAXD). The overall change in hardness was monitored using a texture analyser, a well known empirical technique widely used in industry.

\section{Materials and Methods}

\subsection{Sample composition and storage}

A commercial extruded pet-care product, commonly known as kibble, was studied by standard analytical techniques to report its composition. Protein content was obtained by the Kjeldahl method (AOAC, 1995), fat content was obtained by standard Soxhlet extraction, and glycerol content was calculated with a colorimetric reaction kit (free glycerol determination kit, Sigma Aldrich, Missouri, USA) absorbing at 540nm. 
Non-nitrogenous components, which were associated with the starch fraction, were obtained from the difference in weight fraction. The moisture of the samples was determined gravimetrically using a vacuum oven (Gallemkamp, UK) at $70^{\circ} \mathrm{C}$ for $12 \mathrm{~h}$.

A fresh product ( $24 \mathrm{~h}$ after manufacture), in its original package, was placed in sealed aluminum bags and stored at $37^{\circ} \mathrm{C}$, temperature commonly used in industry for accelerated stability tests (Mizrahi, 2000; Park, Rhee, Kim $\&$ Rhee, 1993; Varga, 2005), for ageing times of 15, 30, 45, 60, 75, 90, 105 and 120 days.

\subsection{Mechanical properties}

The mechanical properties during storage were assessed by measuring the force needed to vertically compress $30 \%$ of the product's height. A texture analyzer model TA.XT-PLUS (Stable Microsystems, UK) was used at a compression speed of $2 \mathrm{~mm} / \mathrm{s}$ using a $70-\mathrm{mm}$ diameter circular plate. The experiment was performed at ambient temperature $\left(\sim 25^{\circ} \mathrm{C}\right)$. Five replicates of each sample were measured.

\subsection{Dynamic mechanical thermal analyzer (DMTA)}

Mechanical properties of the product under dynamic conditions were determined on a Rheometric Scientific Mk III DMTA (Rheometric Scientific, UK) instrument. Fresh and aged samples (30, 60 and 120 days of storage) were cut into flat ribbons of typical size $\sim 1.5 \mathrm{~cm}$ length, $\sim 0.7 \mathrm{~cm}$ width and $\sim 0.2 \mathrm{~cm}$ thickness. The strips were covered with silicone oil (Dow Corning, USA) to avoid moisture loss during analysis. The instrument was set to single bending mode and a temperature scan from $-100{ }^{\circ} \mathrm{C}$ to $120^{\circ} \mathrm{C}$ at a heating rate of $3{ }^{\circ} \mathrm{C} / \mathrm{min}$. To assure the measurement on the stress-strain lineal zone, the set strain was x 4 (62 $\mu \mathrm{m}$ amplitude). The frequency tested was $10 \mathrm{~Hz}$. Three replicates were measured for each sample.

\subsection{Differential scanning calorimetry (DSC)}

Thermal transitions of the product were evaluated using a DSC 7 differential scanning calorimeter (Perkin Elmer, UK) previously calibrated using indium $\left(\mathrm{T}_{\mathrm{m} \text {, onset }}=156.6^{\circ} \mathrm{C}, \Delta \mathrm{H}=28.6 \mathrm{~J} / \mathrm{g}\right)$ and cyclohexane $\left(\mathrm{T}_{\mathrm{m} \text {, onset }}=7.0^{\circ} \mathrm{C}\right)$. Before the analysis all samples were ground under cryogenic conditions using liquid nitrogen and mixed with distilled water at a 1:3 solid-to-water ratio, loaded into stainless steel DSC pans, and equilibrated overnight by continuous rotation at ambient temperature. The typical experimental conditions were: scanning temperature from $5^{\circ} \mathrm{C}$ to $110^{\circ} \mathrm{C}$ at a heating rate of $10^{\circ} \mathrm{C} /$ minute, cooling to $5^{\circ} \mathrm{C}$ at a rate of $30^{\circ} \mathrm{C} /$ minute, and re-heating from $5{ }^{\circ} \mathrm{C}$ to $110^{\circ} \mathrm{C}$ at a rate of $10^{\circ} \mathrm{C} /$ minute. The measuring parameters considered were the endothermic peak temperature and melting enthalpy. The reported transition enthalpies were reported as $\mathrm{J} / \mathrm{g}$ of dry sample. Three replicates were measured for each sample.

\subsection{Wide angle X-ray diffraction (WAXD)}

The samples were scanned using a Bruker D5005 X-Ray diffractometer (Bruker, UK) equipped with a copper source at operational settings of $40 \mathrm{kV}$ and $30 \mathrm{~mA}$ (CuK wavelength $\rightarrow 0.154 \mathrm{~nm}$ ). The experimental settings were an incident angle of $2 \theta=4^{\circ}$ to $38^{\circ}$ at an angle step of $0.05^{\circ}$ per $3 \mathrm{~s}$. The rotational speed of the sample holder was set to $60 \mathrm{rpm}$. The obtained diffractogram were subtracted by the holder spectra and baseline corrected over the measurement scanning angles using the OPUS 3.0 software (Bruker, UK). The fresh and aged samples were scanned in duplicate.

\subsection{Determination of ageing kinetics}

The hardening kinetics was assessed empirically by testing the equation proposed by Avrami (1940) (Equation 1). This model has been successfully applied to various starch-based systems to predict variations in textural attributes relating this phenomenon to a molecular reordering process (Ottenhof, 2003):

$$
Y_{t}=Y_{\infty}\left(Y_{\infty}-Y_{o}\right) e^{-k_{r} t^{n}}
$$

where $n$ represents the Avrami coefficient that is thought to depend on the type of crystal nucleation and the dimensions in which growth takes place, $t$ is variable time, $k_{r}$ is the crystal growth rate, $Y_{t}$ is a physical parameter describing the crystallization dependency over time $t, Y_{o}$ is the physical parameter at time $0, Y_{\infty}$ is the physical parameter at time equal to infinity (end plateau).

\subsection{Statistical analysis}

Statistical significance of the experimental data was evaluated by one-way Analysis of Variance (ANOVA) with a P value of 0.05 using the Data Analysis suite available in Excel Office 2003 (Microsoft Corp. USA). 
The fitting optimization of Equation 1 was done by independently adjusting $Y_{o}, k$ and $n$. This procedure was performed by minimizing the sum of squares difference between the experimental and theoretical data using the Solver software suite available in Excel Office 2003 (Microsoft Corp. USA).

\section{Results and Discussion}

Proximal analysis of the product reported $\sim 20.0 \mathrm{~g}$ of proteins, $\sim 12.5 \mathrm{~g}$ of glycerol, $\sim 2.0 \mathrm{~g}$ of lipids, $16.4 \mathrm{~g}$ of water and $\sim 50.5 \mathrm{~g}$ of starchy components. All quantities are based on $100 \mathrm{~g}$ of dry product. The starch concentration present in the product agreed with the value reported by the manufacturer.

Gravimetric determination showed a small variation in moisture content between the fresh and aged product after 60 and 120 days (Table 1). The statistical analysis of this data did not indicate significant differences $(P>0.05)$. Therefore, it was concluded that the product did not dehydrate during storage.

The mechanical properties of the product measured by texture analysis showed a significant increase in stiffness during storage as indicated by greater compressive force. This behavior can be clearly seen in Figure 1. In the first 30 days of storage there was a slight increase $(\mathrm{P}>0.05)$ of this parameter from $\sim 25 \mathrm{~N}$ to $\sim 32 \mathrm{~N}$. After 30 days of storage a marked increase $(\mathrm{P}<0.05)$ of the compression force was detected up to $\sim 60$ days of storage, with an increase from $\sim 32 \mathrm{~N}$ to $\sim 80 \mathrm{~N}$. At this point the compression curve leveled off with a plateau value of $\sim 82 \mathrm{~N}(\mathrm{P}<0.05)$ up to 120 days of storage. As mentioned previously, this increase in stiffness was not related to product dehydration, as the moisture content remained relatively constant during the experiment (Table 1), suggesting other mechanisms driving the hardening of the system. Pushpadass and Hanna (2009) showed that both tensile strengths and strains in extruded corn starch films plasticized with glycerol and stearic acid were strongly influenced by aging time $\left(120\right.$ days, $\left.20^{\circ} \mathrm{C}\right)$, where tensile strengths increased during storage while tensile strain decreased with aging time, making films stiffer and less flexible. This behavior was explained by changes in the microstructure driven by increasing in crystalline content and free volume changes (Pushpadass \& Hanna, 2009).

The experimental data obtained from DMTA show the typical profile for a polymeric structure (Figures 2A and B), which is interesting for such a complex composition. The elastic modulus (E') significantly decreased three-fold from $\log E^{\prime} \sim 9.3 \mathrm{~Pa}$ to $\log E^{\prime} \sim 6.0 \mathrm{~Pa}$ when the temperature increased from $-100{ }^{\circ} \mathrm{C}$ to $40^{\circ} \mathrm{C}$. This reduction of three orders of magnitude was coupled to a maximum value of $\tan \delta \sim 0.65$ at $\sim 20^{\circ} \mathrm{C}$. This behavior can be related to an $\alpha$-like relaxation of the main polymer chains at the glass transition temperature. At this point, long range and cooperative motions of the polymeric chains seems to occur, increasing their structural mobility (Price, 2002; Roos, 2010). These data suggest that the physical state of the overall mixture, and particularly the starchy component present in the formulation, were in a rubber-like state under normal environmental conditions $\left(\mathrm{T} \geq 25^{\circ} \mathrm{C}\right)$. These experimental data correlated well with the flexible nature of the food product at ambient temperature (data not shown). The $\tan \delta$ vs. temperature graph also indicated a second transition at lower temperature $\left(\sim-40{ }^{\circ} \mathrm{C}\right)$ with an associated $\tan \delta \sim 0.40$ (Figure 2B). The origin of this transition is not clear, but it may represent a secondary or $\beta$-relaxation of the polymer structure (Kalichevsky, Jaroszkiewicz, Ablett, Blanshard, \& Lillford, 1992; Price, 2002) or an $\alpha$-relaxation from a separated phase or rich fraction of a secondary component. The experimental data suggest a rich region of the protein fraction present in the formulation. A similar behavior has been reported in the literature using mechanical spectroscopy to study a gelatin-starch model system (Mousia, Farhat, Blachot \& Mitchell, 2000).

Similar $E^{\prime}$ values were found between the fresh and aged samples at temperatures lower than $20^{\circ} \mathrm{C}$. In this temperature range the amorphous fraction would be in the glassy state, behaving mechanically as a solid, therefore stiffness variations between the samples were not observed. At higher temperatures significant differences $(\mathrm{P}<0.05)$ in $E^{\prime}$ values were obtained. Indeed, if the reference temperature is set at $25^{\circ} \mathrm{C}$ (ambient temperature), clear differences in this parameter between the fresh product and that aged for 120 days were observed, with $\log E^{\prime} \sim 6.3 \mathrm{~Pa}$ to $\log E^{\prime} \sim 6.7 \mathrm{~Pa}$, respectively (Figure 2A). These results correlate well with the experimental data from the compression tests performed at $\sim 25^{\circ} \mathrm{C}$, where significant changes in compressive force were detected for the same storage time (Figure 1).

No variations were observed in the temperatures at which the marked drop in $E$ ' values and $\tan \delta$ peaks occurred for the fresh and aged samples (Figures 2A and B). As moisture, an effective plasticizer, remained relatively constant throughout the storage evaluation, no change in these transition temperatures was observed.

Interestingly, a decrease in $\tan \delta$ peak height was observed during storage (Figure 2B). This value decreased from $\tan \delta \sim 0.65$ for the fresh product to $\tan \delta \sim 0.40$ after 120 days of storage. This behavior may be associated with the reduction of the amorphous fraction present in the system, suggesting a possible reordering phenomenon occurring during storage (Price, 2002). Lionetto, Maffezzoli, Ottenhof, Farhat, and Mitchell (2005) 
studied an extruded wheat starch with $37 \%$ moisture content $(\mathrm{db})$ stored for $180 \mathrm{~h}$, explaining the decrease in tan $\delta$ values from $\sim 0.85$ to $\sim 0.25$ by a re-crystallization phenomenon, which was in agreement with X-ray diffractograms (increase in relative intensity at around $2 \theta \sim 16^{\circ}, \sim 18^{\circ}$ and $\sim 23.5^{\circ}$ ) and NMR relaxometry (decrease in relaxation time, $\mathrm{T}_{2}$ ) during storage representing lower molecular mobility. Figure $2 \mathrm{~B}$ also indicates a reduction in $\tan \delta$ of the smaller peak occurring at $-40{ }^{\circ} \mathrm{C}$, from $\sim 0.39$ to $\sim 0.32$, supporting the hypothesis that attributes the origin of this transition to the presence of a separated phase component changing its molecular configuration on ageing. Mousia et al. (2000) studied the mechanical transitions of amylopectin-gelatin mixtures by mechanical spectroscopy and attributed the presence of a transition at lower temperatures to the existence of a gelatin-rich phase present in the mixture.

Figures $3 \mathrm{~A}$ and $\mathrm{B}$ depict the $1^{\text {st }}$ and $2^{\text {nd }}$ DSC scans, respectively. The experimental data show a small reversible endotherm at $\sim 25^{\circ} \mathrm{C}$ with a melting enthalpy $\left(\Delta \mathrm{H}_{\mathrm{m}}\right)$ of $\sim 0.3 \mathrm{~J} / \mathrm{g}$, which was associated with the melting of lipids present in the formulation. This was confirmed by a reduction of this enthalpy when the product was thoroughly washed by an organic solvent (data not shown). As expected, the $\Delta \mathrm{H}_{\mathrm{m}}$ values did not change significantly with storage time (Table 2). The DSC scans obtained for the fresh product and that stored for 30 days showed a small endotherm at $\sim 58^{\circ} \mathrm{C}$ with an associated $\Delta \mathrm{H}_{\mathrm{m}} \sim 0.10 \mathrm{~J} / \mathrm{g}$. This value would suggest some structural ordering of the starchy components present in the formulation. Major endotherm enthalpies were detected at the same temperature range for the product aged for 60 and 120 days, with $\Delta \mathrm{H}_{\mathrm{m}} \sim 1.03 \mathrm{~J} / \mathrm{g}$ and $\Delta \mathrm{H}_{\mathrm{m}} \sim 2.10 \mathrm{~J} / \mathrm{g}$, respectively (Table 2), indicating further ordering of the structure. If the cereal (starch) weight fraction present in the formulation is considered, the melting temperatures and enthalpies obtained are equivalent to those found in the literature for the starch-water system. Indeed, Ottenhof, Hill and Farhat (2005) suggested that retrogradation kinetics of starch-water systems prepared by thermo-mechanical extrusion showed endothermic transitions at peak temperatures of $57.7^{\circ} \mathrm{C}\left(\Delta \mathrm{H}_{\mathrm{m}} \sim 11.06 \mathrm{~J} / \mathrm{g}\right), 55.8^{\circ} \mathrm{C}\left(\Delta \mathrm{H}_{\mathrm{m}} \sim 9.0 \mathrm{~J} / \mathrm{g}\right)$ and $53.0^{\circ} \mathrm{C}\left(\Delta \mathrm{H}_{\mathrm{m}} \sim 6.1 \mathrm{~J} / \mathrm{g}\right)$ for potato, waxy maize and wheat starches, respectively.

X-ray diffractograms for the fresh and aged product in Figure 4 show a small peak for all the samples at a diffractive angle $(2 \theta) \sim 32^{\circ}$, which was related to the presence of a salt in crystalline form. Enrione (2005) detected diffractive peaks at $\sim 30^{\circ}$ in a similar formulation which was related to the presence of potassium carbonate $\left(\mathrm{K}_{2} \mathrm{CO}_{3}\right)$.

The curves for the fresh samples and those stored for 30 days were very similar, showing an amorphous-like pattern with not distinctive peak being detected. In the case of the product stored for 60 and 120 days, Figure 4 shows an indication of structural order taking place, represented by two peaks standing out from the background, one at a diffraction angle $(2 \theta) \sim 20^{\circ}$ and the other at $2 \theta \sim 23^{\circ}$. These peaks seem to be related to the formation of a rather ordered structure of the starchy component (Ottenhof et al., 2005). Bello-Perez, Ottenhof, Agama-Acevedo and Farhat (2005) detected an increase in peak intensity at the angles (20) $\sim 17^{\circ}$ and $23^{\circ}$ when extruded banana starch with a moisture content of $30 \%(\mathrm{wb})$ was stored for $7 \mathrm{~h}$ at $25{ }^{\circ} \mathrm{C}$. Similar results were reported by Pushpadass and Hanna (2009) working with extruded corn starch films plasticized with glycerol and stearic acid stored at $\sim 20^{\circ} \mathrm{C}$ for up to 120 days. Saiah, Sreekumar, Leblanc, Castandet and Saiter (2007) also reported an increase in crystallinity measured by X-ray diffraction in wheat extruded sheets plasticized with water and glycerol after storage of 12 months at room temperature.

The reordering process of the polymeric fraction, particularly the starchy component present in the formulation, suggests the relevance of the application of a mathematical representation of the experimental data in order to assess the kinetics of this phenomenon. Figure 1 shows the fitting of the Avrami equation (Equation 1) generating the parameters $k \sim 6.4 \mathrm{E}-06, n \sim 2.90, Y_{\infty} \sim 84.0 \mathrm{~N}$ and $\mathrm{Y}_{\mathrm{o}} \sim 27.0 \mathrm{~N}$. If retrogradation is assumed to be the main mechanism driving the changes in mechanical properties of the product, the rate of retrogradation $\left(\mathrm{G} \mathrm{h}^{-1}\right)$ was then calculated using the relation $G=k_{r}{ }^{1 / n}$ (Farhat et al., 2000), giving a value of $\sim 1.6 \mathrm{E}-02 \mathrm{~h}^{-1}$. This value was similar in order of magnitude to those indicated in the literature for extruded starch-based systems. Ottenhof et al. (2005) obtained a $G$ value of $\sim 5.0 \mathrm{E}-02 \mathrm{~h}^{-1}$ for extruded wheat starch systems in the presence of $34.1 \%$ (d.w.b) of moisture, and Enrione (2005) calculated a $G$ value of $\sim 6.5 \mathrm{E}-02 \mathrm{~h}^{-1}$ for wheat starch extrudates containing $16 \%$ moisture $(\mathrm{wb})$ and $20 \%$ glycerol $(\mathrm{db})$. Despite the usefulness of using this equation to assess the recrystallization kinetics of these systems, the interpretation of the Avrami coefficients should be treated with caution. Del Nobile, Martoriello, Mocci and La Notte (2003) commented that parameter $n$ should be considered as a fitting variable rather than of the original interpretations of an integer number representing the mechanism of crystal growth. Farhat et al. (2000) used a least squares minimizing fitting routine to adjust parameters $k, n, Y_{\infty}$ and $Y_{o}$ instead of simple linear fitting because they considered that the model's assumptions would introduce distortions in the calculated kinetic parameters. 
Therefore, more suitable mathematical models are necessary in order to improve the understanding of the retrogradation process and kinetics in complex food formulations.

\section{Conclusions}

The results indicate the relevance and importance of fundamental techniques to assess the structure and stability of complex food systems during storage. Particularly interesting in this work are the data obtained from mechanical spectroscopy showing a clear glass transition temperature properly describing the rubber-like structure of the product at ambient temperature. Transitions at lower temperatures indicated the presence of a protein-rich fraction present in the formulation. The hardening of the product during storage, indicated by an increase in the elastic modulus and compression force, was correlated to a reordering of amylopectin from the starchy component as indicated by melting endotherms detected by differential calorimetry. These data were supported by the reduction of the $\tan \delta$ values at constant temperature reported for the stored product. This phenomenon was also observed by X-ray diffraction after 120 days of storage. The crystallization kinetics, calculated by the Avrami equation, was comparable to values reported in the literature for starch-based model systems, confirming the functionality of this biopolymer as structuring matrix in extruded foods products.

Abbreviations: Tg, glass transition temperature; DMTA, dynamic mechanical thermal analyser; DSC, differential scanning calorimetry; WAXD, wide angle X-ray diffraction; Aw, water activity; t, time; $\mathrm{k}_{\mathrm{r}}$, crystal growth rate; $Y_{t}$, physical parameter describing the crystallization dependency on time $t ; Y_{o}$, value of physical parameter at time equal $0 ; Y_{\infty}$, value of physical parameter at time equal infinity (end plateau); E', elastic modulus; $G$, rate of retrogradation.

\section{References}

AOAC (1995). Official Methods of Analysis of AOAC International. (16th ed.) Washington DC: Association of Official Analytical Chemist.

Avrami, M. (1940). Kinetics of phase change. II Transformation-time relations fro random distribution of nuclei. The Journal of Chemical Physics, 8, 212-224. http://dx.doi.org/10.1063/1.1750631

Bello-Perez, L. A., Ottenhof, M. A., Agama-Acevedo, E., \& Farhat, I. A. (2005). Effect of Storage Time on the Retrogradation of Banana Starch Extrudate. Journal of Agricultural and Food Chemistry, 53, 1081-1086. http://dx.doi.org/10.1021/jf048858I

Del Nobile, M. A., Martoriello, T., Mocci, G., \& La Notte, E. (2003). Modeling the starch retrogradation kinetic of durum wheat bread. Journal of Food Engineering, 59, 123-128. http://dx.doi.org/10.1016/S0260-8774(02)00441-7

Enrione, J. (2005). Mechanical Stability of Intermediate Moisture Starch-Glycerol Systems. PhD Thesis. Division of Food Sciences, The University of Nottingham.

Farhat, I. A., Blanshard, J. M. V., \& Mitchell, J. R. (2000). The retrogradation of waxy maize starch starch-sugar extrudates. Biopolymers, 53, 411.

Farhat, I. A., Blanshard, J. M. V., Decamps, M., \& Mitchell, J. R. (2000). Effect of Sugars on Retrogradation of Waxy Maize Starch-Sugar Extrudates. Cereal Chemistry, 77, 202-208. http://dx.doi.org/10.1094/CCHEM.2000.77.2.202

Fennema, O. R. (1996). Food Chemistry. (3rd ed.). New York: CRC Press.

Gray, J. A., \& Bemiller, J. N. (2003). Bread Staling: Molecular Basis and Control. Comprehensive Reviews in Food Science and Food Safety, 2, 1-21. http://dx.doi.org/10.1111/j.1541-4337.2003.tb00011.x

Jagannath, J. H., Jayaraman, K. S., Arya, S. S., \& Somashekar, R. (1998). Differential scanning calorimetry and wide-angle X-ray scattering studies of bread staling. Journal of Applied Polymer Science, 67, 1597-1603.

Jouppila, K., Kansikas, J., \& Roos, Y. H. (1998). Factors affecting crystallization and crystallization kinetics in amorphous corn starch. Carbohydrate Polymers, 36, 143-149. http//dx.doi.org/10.1016/SO144-8617(98)00024-1

Kalichevsky, M., Jaroszkiewicz, E. M., Ablett, S., Blanshard, J. M. V., \& Lillford, P. J. (1992). The Glass Transition of Amylopectine Measured by DSC, DMTA and NMR. Carbohydrate Polymer, 18, 77-88. http://dx.doi.org/10.1016/0144-8617(92)90129-E

Karim, A., Norziah, M. H., \& Seow, C. C. (2000). Methods for the study of starch retrogradation. Food Chemistry, 71, 9-36. http://dx.doi.org/10.1016/S0308-8146(00)00130-8

Kingcam, R., Devahastin, S., \& Chiewchan, N. (2008). Effect of starch retrogradation on texture of potato chips produced by low-pressure superheated steam drying. Journal of Food Engineering, 89, 72-79. http://dx.doi.org/10.1016/j.jfoodeng.2008.04.008 
Kun, S., Ping, Q., Li-Jun, W., Zhan-hui, L., \& Li-Te, L. (2007). Effect of Storage Time on the Physicochemical and Sensory Properties of Man-tou (Chinese Steamed Bread). International Journal of Food Engineering, 3, 1-19. http://dx.doi.org/10.2202/1556-3758.1217

Li, Y., Szlachetka, K., Chen, P., Lin, X., \& Ruan, R. (2008). Ingredient Characterization and Hardening of High-Protein Food Bars: an NMR State Diagram Approach. Cereal Chemistry, 85, 780-786. http://dx.doi.org/10.1094/CCHEM-85-6-0780

McMahon, D. J., Adams, S. L., \& McManus, W. R. (2009). Hardening of High-Protein Nutrition Bars and Sugar/Polyol-Protein Phase Separation. Journal of Food Science, 74, E312-E321. http://dx.doi.org/10.1111/j.1750-3841.2009.01225.x

Mizrahi, S. (2000). Accelerated shelf-life test. In D. Kilcast \& P. Subramaniam (Eds.), The stability and shelf-life of foods. Florida: CRC/Woodhead.

Mizuno, A., Mitsuiki, M., \& Motoki, M. (1998). Effect of Crystallinity on the Glass Transition Temperature of Starch. Journal of Agricultural and Food Chemistry, 46, 98-103. http://dx.doi.org/10.1021/jf970612b

Mousia, Z., Farhat, I. A., Blachot, J. F., \& Mitchell, J. R. (2000). Effect of water partitioning on the glass-transition behaviour of phase separated amylopectin-gelatin mixtures. Polymer, 41, 1841-1848. http://dx.doi.org/10.1016/S0032-3861(99)00335-3

Ottenhof, M. A. (2003). A multi-technique study of the retrogradation of concentrated starch systems. PhD Thesis. Division of Food Sciences, The University of Nottingham.

Ottenhof, M.-A., Hill, S. E., \& Farhat, I. A. (2005). Comparative Study of the Retrogradation of Intermediate Water Content Waxy Maize, Wheat, and Potato Starches. Journal of Agricultural and Food Chemistry, 53, 631-638. http://dx.doi.org/10.1021/jf048705y

Park, J., Rhee, K. S., Kim, B. K., \& Rhee, K. C. (1993). High-Protein Texturized Products of Defatted Soy Flour, Corn Starch and Beef: Shelf-Life, Physical and Sensory Properties. Journal of Food Science, 58, 21-27. http://dx.doi.org/10.1111/j.1365-2621.1993.tb03202.x

Price, D. M. (2002). Thermomechanical, Dynamic Mechanical and Dielectric Methods. In P.J. Heines (Eds), Principles of Thermal Analysis and Calorimetry. Cambridge: The Royal Society of Chemistry. http://dx.doi.org/10.1039/9781847551764-00094

Pushpadass, H. A., \& Hanna, M. A. (2009). Age-Induced Changes in the Microstructure and Selected Properties of Extruded Starch Films Plasticized with Glycerol and Stearic Acid. Industrial \& Engineering Chemistry Research, 48, 8457-8463. http://dx.doi.org/10.1021/ie801922z

Roos, Y. H. (2010). Glass Transition Temperature and Its Relevance in Food Processing. Annual Review of Food Science and Technology, 1, 469-496. http://dx.doi.org/10.1146/annurev.food.102308.124139

Saiah, R., Sreekumar, P. A., Leblanc, N., Castandet, M., \& Saiter, J. M. (2007). Study of Wheat-Flour-Based Agropolymers: Influence of Plasticizers on Structure and Aging Behavior. Cereal Chemistry Journal, 84, 276-281. http://dx.doi.org/10.1094/CCHEM-84-30276

Takaya, T., Sano, C., \& Nishinari, K. (2000). Thermal studies on the gelatinisation and retrogradation of heat-moisture treated starch. Carbohydrate Polymers, 41, 97-1000.

Torney, A. A, Unlu, E., Willcocks, N., Zubair, K., \& Bierer, T. (2009). Method for designing an oral pet product using biometric analysis. United States Patent Application Publication, Pub. No: US 2008/0010080 A1.

Van Soest, \& Knooren, N. (1997). Influence of glycerol and water content on the structure and properties of extruded starch plastic sheets during aging. Journal of Applied Polymer Science, 64, 1411-1422.

Varga, L. (2005). Use of a long-chain polyphosphate mixture for shelf-life extension of processed cheese spreads. Acta Alimentaria, 34, 493-498. http://dx.doi.org/10.1556/AAlim.34.2005.4.16

Table 1. Moisture content (MC) of fresh and aged commercial product

\begin{tabular}{ll}
\hline \multicolumn{1}{c}{ Storage time } & \multicolumn{1}{c}{ MC $(\%$, wet basis $)$} \\
\hline Fresh & $16.2(0.3)$ \\
60 days & $16.2(0.2)$ \\
120 days & $15.2(0.2)$ \\
\hline
\end{tabular}

Values in brackets are the standard deviation from 3 measurements. 
Table 2. DSC endotherms and enthalpy of fresh and aged products stored for 30,60 and 120 days at $37^{\circ} \mathrm{C}$.

\begin{tabular}{lcccc}
\hline & $\begin{array}{c}1^{\text {st }} \text { peak } \\
\text { Temperature }\left({ }^{\circ} \mathrm{C}\right)\end{array}$ & $\begin{array}{c}1^{\text {st }} \text { Peak } \\
\text { Enthalpy }(\mathrm{J} / \mathrm{g})\end{array}$ & $\begin{array}{c}2^{\text {nd }} \text { peak } \\
\text { Temperature }\left({ }^{\circ} \mathrm{C}\right)\end{array}$ & $\begin{array}{c}2^{\text {nd }} \text { Peak } \\
\text { Enthalpy }(\mathrm{J} / \mathrm{g})\end{array}$ \\
\hline Fresh $1^{\text {st }}$ scan & $25.4(1.2)$ & $0.33(0.08)$ & $56.1(1.7)$ & $0.12(0.03)$ \\
Fresh $2^{\text {nd }}$ scan & $25.2(1.8)$ & $0.31(0.06)$ & & \\
Aged 30 days $1^{\text {st }}$ scan & $24.1(1.3)$ & $0.28(0.05)$ & $57.4(1.6)$ & $0.11(0.04)$ \\
Aged 30 days $2^{\text {nd }}$ scan & $24.9(1.6)$ & $0.25(0.07)$ & & \\
Aged 60 days $1^{\text {st }}$ scan & $25.5(1.3)$ & $0.26(0.05)$ & $57.1(1.4)$ & $1.03(0.32)$ \\
Aged 60 days $2^{\text {nd }}$ scan & $25.1(1.1)$ & $0.25(0.09)$ & & $2.10(0.39)$ \\
Aged 120 days $1^{\text {st }}$ scan & $25.3(0.8)$ & $0.28(0.05)$ & $58.6(1.9)$ & \\
Aged 120 days $2^{\text {nd }}$ scan & $25.4(1.2)$ & $0.31(0.03)$ & & \\
\hline
\end{tabular}

$(*)$ values in brackets represent the standard deviation from 3 measurements.

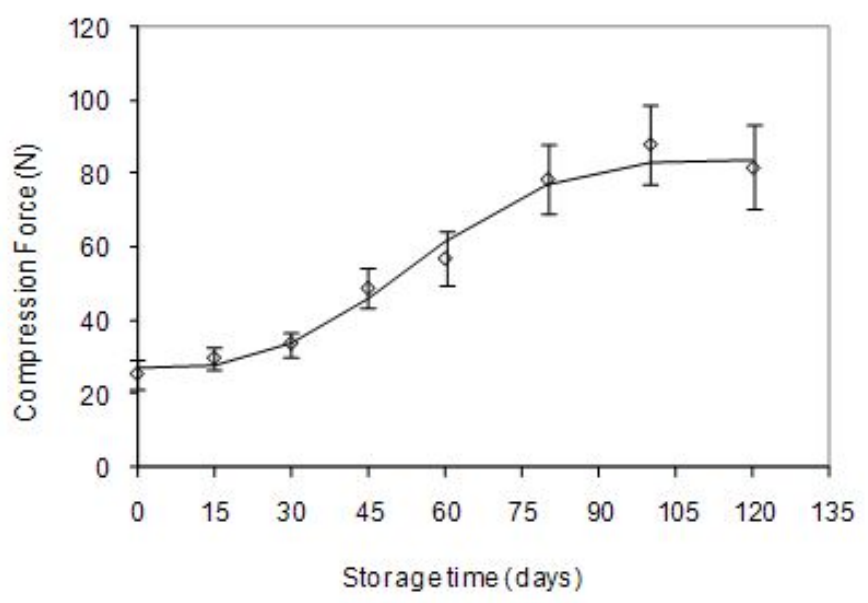

Figure 1. Changes in the compression force of the product versus storage time at $37^{\circ} \mathrm{C}$. Error bars represent the standard deviation from 5 measurements
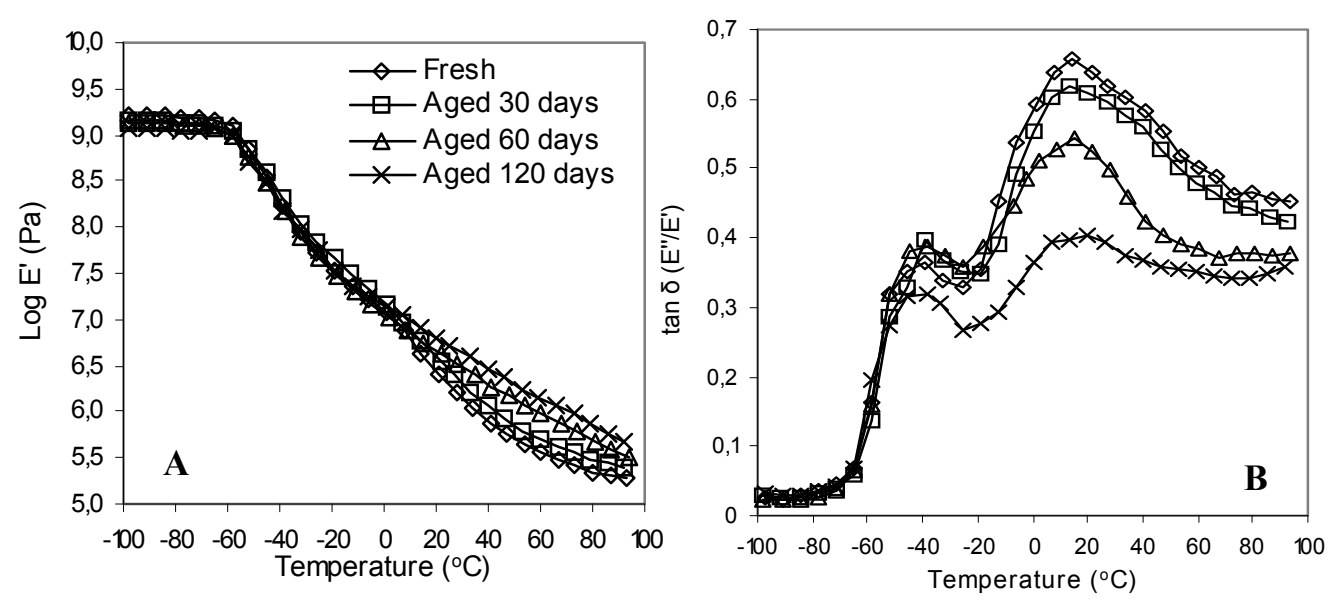

Figure 2. Elastic modulus $E^{\prime}$ (A) and $\tan \delta$ (B) versus temperature for the commercial product stored for 0,30 , 60 and 120 days at $37^{\circ} \mathrm{C}$. Analysis performed at $10 \mathrm{~Hz}$ 

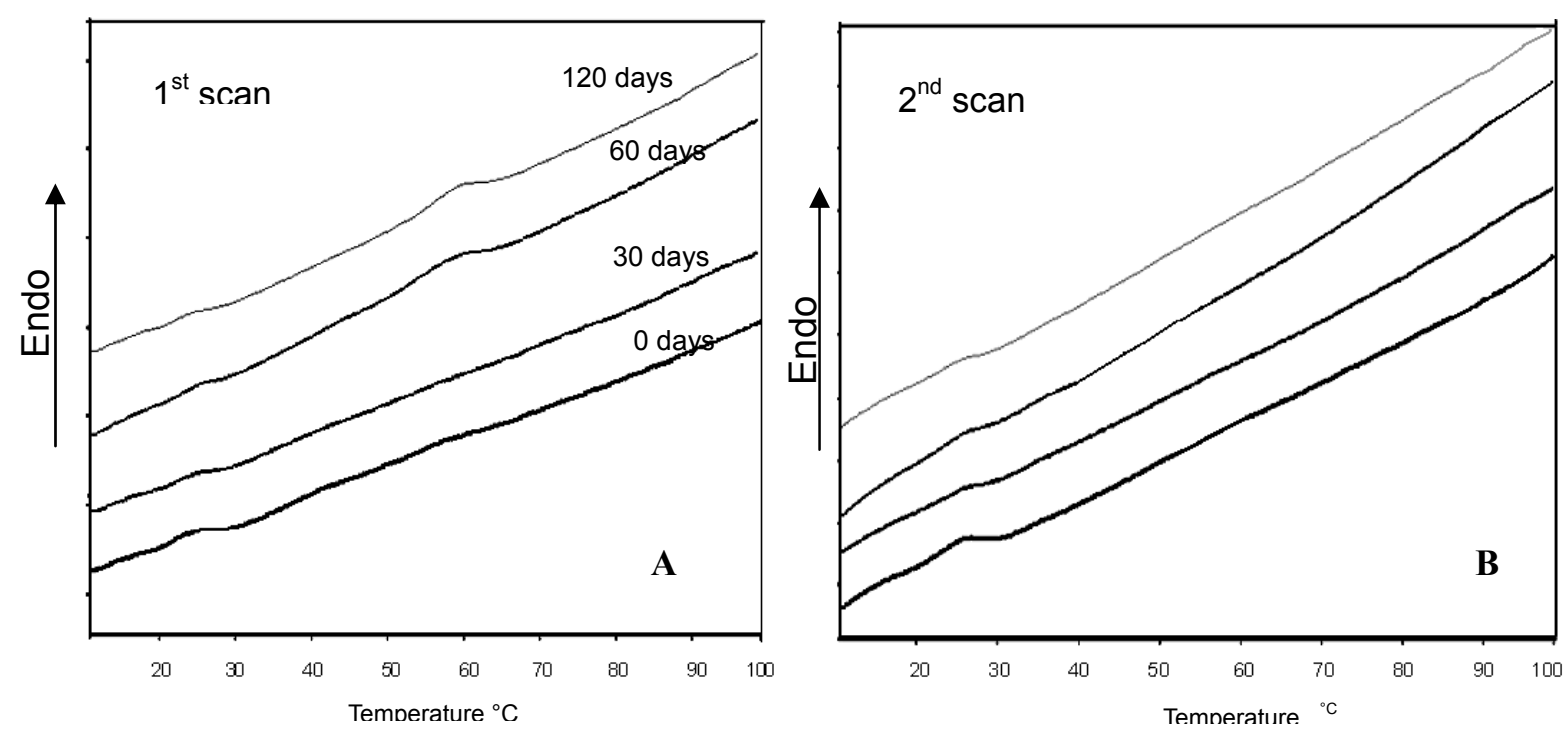

Figure $3.1^{\text {st }}$ and $2^{\text {nd }}$ DSC scans for fresh and 30,60 and 120 days stored product at $37{ }^{\circ} \mathrm{C}$

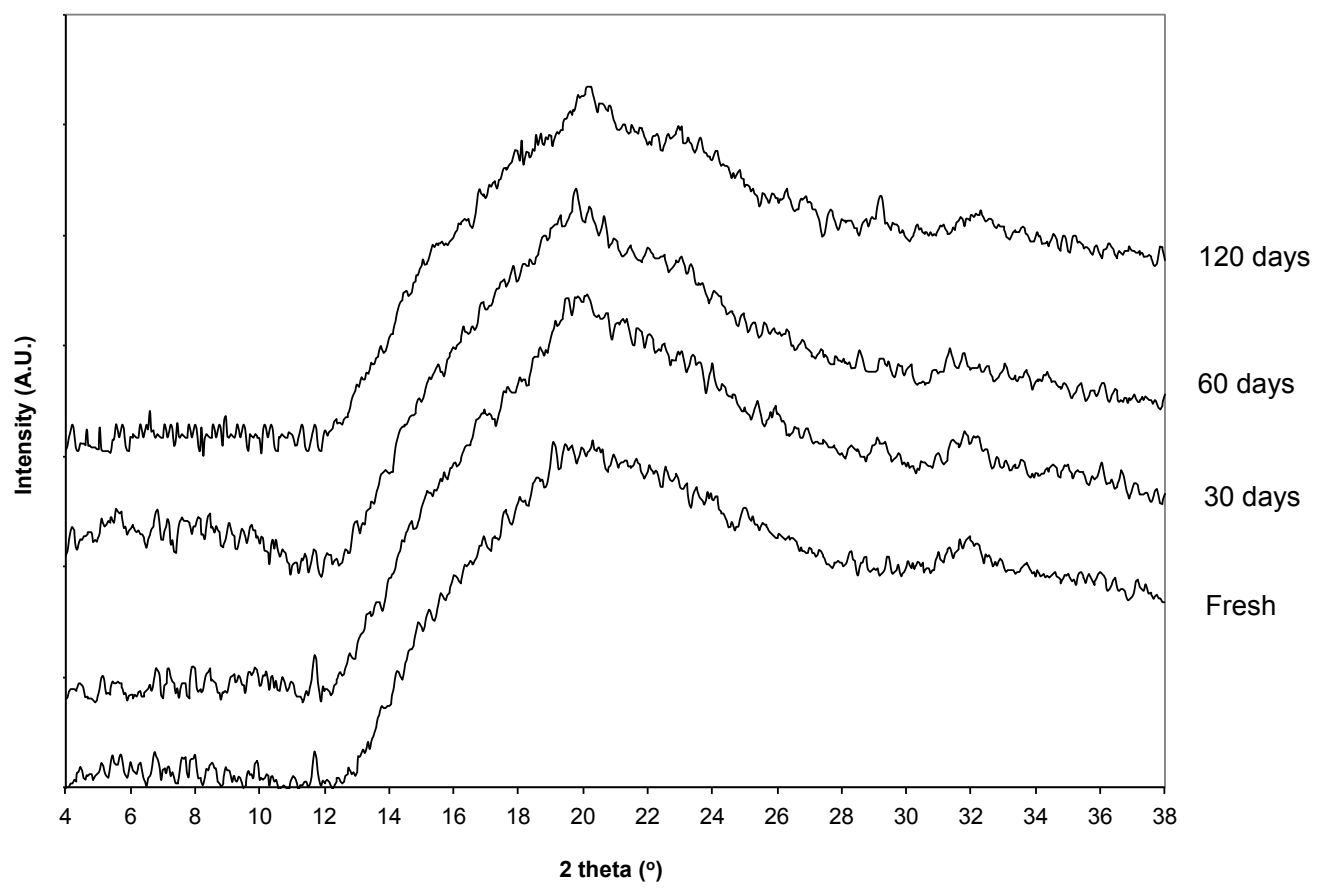

Figure 4. X-ray diffractograms for fresh product and product stored for 30,60 and 120 days at $37^{\circ} \mathrm{C}$. (A. U.: Arbitrary Units) 